\title{
Effect of Epidermal Growth Factor and Artificial Feeding in Suckling Rats
}

\author{
MARY C. MOORE, HARRY L. GREENE, HAMID M. SAID, FAYEZ K. GHISHAN, AND \\ DAVID N. ORTH \\ Vanderbilt University School of Medicine, Clinical Nutrition Research Unit Laboratory, Medical Center North, \\ Nashville, Tennessee 37232
}

\begin{abstract}
To evaluate the effects of epidermal growth factor (EGF) in dietary milk, a new method of delivering an artificial (EGF-deficient) formula was developed using 42 rat pups, 1-14 days of age. In a second study the effect of EGF was evaluated in suckling rats from 3-11 days of age: group 1, mother-fed; group 2, mother-fed plus daily injections of EGF $(0.1 \mu \mathrm{g} / \mathrm{g}$ body weight $)$; group 3 , artificial milk fed with added EGF $(62 \mathrm{ng} / \mathrm{ml})$; and group 4 , artificial milk fed without EGF. Each group consists of nine rats. In group 2 there was premature eye opening and tooth eruption and a significant reduction in body weight and weight of liver, kidney, thyroid, and thymus but an increase in length of the intestine and weights of stomach, pancreas, lung, and adrenal $(p<0.04)$, when compared to group 1 . Both groups 3 and 4 showed premature tooth eruption and eye opening, and their body weights and most organ weights were similar to group 2; exceptions were a smaller stomach, thyroid, thymus, lung, and adrenal, which were similar to those in group 1. In addition, intestinal length in groups 3 and 4 were similar to the mother-fed EGF-treated pups (group 2). There was no difference in intestinal length between the artificially fed pups, whether or not they received oral EGF. These findings demonstrate a new and effective technique of artificial feeding and suggest that the increase in intestinal length caused by injections of EGF $(0.1 \mu \mathrm{g} / \mathrm{g}$ body weight) can also be induced by feeding an artificial milk with or without physiologic levels of EGF. (Pediatr Res 20: 1248-1251, 1986)
\end{abstract}

Abbreviation

EGF, epidermal growth factor

Artificial feeding of infant rats provides a useful model for study of the effect of various nutritive and nonnutritive milk constituents during early development (1), as well as psychological effects of social deprivation (2). Most investigators, however, have utilized gastrostomized rats fed a formula based on evaporated or whole cow's milk (1-7). The invasive nature of the gastrostomy and the inability to decrease or delete a particular nutrient in the formula are serious shortcomings of these proce-

Received May 27, 1986; accepted July 11, 1986

Author to whom all correspondence and reprint requests should be sent Harry L. Greene, M.D., Department of Pediatrics, Division of Gastroenterology and Nutrition, Vanderbilt University School of Medicine, D-4130, Medical Center North, Nashville, TN 37232.

Supported by NIH NIADDKD AM 26657 05, Mead Johnson Nutrition Division, and Sandoz Nutrition. dures. Herein we describe a new method for orogastric feeding of newborn infant rats with a modular formula which can be modified in most of its nutritive and nonnutritive constituents. In addition, with the use of this method of artificial feeding we report the findings seen with and without the addition of EGF to milk.

EGF is a peptide with mitogenic properties in vitro and in vivo $(8,9)$. It is present in the milk of most species, including man $(10,11)$. It is resistant to acid hydrolysis $(1,12)$ and pancreatic enzyme digestion (13), has specific receptors on intestinal epithelial cells (14), and can be absorbed intact in suckling rats (15). For these reasons, it is postulated that milk-derived EGF plays an important physiological role during development. Previous studies have evaluated pharmacological doses of EGF given orally or systemically in addition to that normally consumed in physiological amounts in maternal milk, and therefore do not examine the physiological role of milk-derived EGF in normal development. Use of artificial milk, free of EGF provides a tool with which to evaluate the animals' response to artificial milk with and without addition of physiological concentrations of EGF. This study reports the effects of EGF given systemically to mother-fed pups and compares them to the effects of an artificial diet, with or without EGF, fed during the first 2 wk of life.

\section{METHODS}

To develop the technique of artificial feeding, a series of four studies was performed. In each of the four studies, pups from three litters were pooled and 12 pups to receive tube feeding were paired by weight with 12 rats to a mother-fed group. Each group had their studies initiated on a different day of life, days $1,2,3$, and 5 . Feedings were maintained for 7 days, with the exception of the pups begun on day 5 , which were maintained for 9 days. Because of six deaths in the tube-fed group a total of 42 pups was evaluated for tube feeding for the full period of time. In a second study this model for orogastric feeding was used to study the effects of dietary EGF. In this study, 3-day-old pups were randomly assigned by weight to one or two groups: 1) a normally reared group remaining with lactating females $(n=$ $18)$ or 2$)$ an artificially-reared group $(n=18)$ receiving intragastric tube feeding.

Intragastric feeding. A silicone rubber (Silastic, Dow Corning Corp., Midland, MI) orogastric feeding tube was prepared for each artificially fed rat. One end of the $35-\mathrm{cm}$ length of tubing (internal diameter, $0.635 \mathrm{~mm}$; external diameter, $1.3 \mathrm{~mm}$ ) was placed in hexane for approximately $45 \mathrm{~s}$ to cause the end to flare. One end of the $5.7 \mathrm{~cm}$ length of tubing (internal diameter 0.305 $\mathrm{mm}$; external diameter $0.635 \mathrm{~mm}$ ) was inserted inside the flared larger tube so that the two overlapped approximately $1 \mathrm{~cm}$. The hexane was allowed to dry so that the two tubes fit together snugly, and the junction of the two tubes was sealed with cyanoacrylate glue (Krazy Glue, Inc., Itasca, IL). The smaller tube 
was gently inserted into the pup's mouth and pushed down the esophagus until a sufficient amount was introduced to reach the stomach. No stylet was required for placement of the tube. The tube was then fastened to the pup's lip and to the side or top of its head and body with cyanoacrylate glue.

Pups were housed in individual styrofoam cups $(10.2 \mathrm{~cm}$ in diameter; $7.6 \mathrm{~cm}$ deep) with tightly fitting lids. Holes were cut in the lids to allow ventilation and admit the feeding tube. The cups were counter-weighted as described by Hall (2) to prevent capsizing and floated in a water bath maintained at $37-40^{\circ} \mathrm{C}$ by an aquarium heater (Ebo-Jager, El Segundo, CA).

The anogenital area of the pups was stroked gently every $4 \mathrm{~h}$ to stimulate voiding and defecation $(3,5)$. Wood chips, used as bedding in the cups, were changed daily.

The free end of the feeding tube was connected to a formulafilled syringe with a 21 -gauge blunt needle. The syringes were mounted on an infusion pump (Harvard Apparatus, Model 2265, South Natick, MA), which delivered the formula continuously over a 24-h period. Pups were weighed at the same time daily. Each pup received approximately $0.5 \mathrm{kcal} / \mathrm{g}$ body weight per day (4). Eye opening and tooth eruption was evaluated twice daily and agreed upon by two individuals.

The formula was prepared daily in either 50 or $100 \mathrm{ml}$ amounts, and no more than $12 \mathrm{~h}$ supply was placed in the syringes at one time. The formula was mixed by placing all the ingredients in Table 1 in a Sorvall-Omni-mixer and blended for $3 \mathrm{~min}$. The nutritional composition of the formula and a comparison with rat milk are shown in Table 2 . The osmolality of the formula determined by freezing point depression was 457 mosmol $/ \mathrm{kg}$ and by vapor pressure method $452 \mathrm{mosmol} / \mathrm{kg}$.

EGF studies. Mother-Fed Rats. In an effort to promote similar dietary intakes in all maternally fed rats, the pups were pooled and randomly assigned to two mothers. Pups of similar weights were paired to receive either EGF $(0.05 \mu \mathrm{g} / \mathrm{g}$ body weight twice daily) or an equal volume of the EGF vehicle twice daily throughout the study.

Intragastrically Fed Rats. To ensure that weights were identical in each of the treatment groups, pups previously selected to receive tube feeding were again pooled and randomly assigned to receive the artificial formula containing no EGF (measured level was undetectable by radioimmunoassay) or added mouse EGF (measured level $62 \mathrm{ng} / \mathrm{ml}$ ), this dose approximates the concentration of EGF measured in milk collected between 4 and 8 days of lactation from four nursing rat dams. Initially, there were nine rats in each treatment group to allow for death or illness during the course of the study.

Mouse EGF was prepared from the submandibular glands of male mice by the method of Savage and Cohen (16). It had full biological activity, as assessed by radioreceptor assay (17) and

Table 1. Ingredients of tube feeding formula

\begin{tabular}{lc}
\hline Protein (Nutrisource, Sandoz Nutrition Corp.) & $9.1 \mathrm{~g}^{*}$ \\
Lactose (Sigma Chemicals) & $2 \mathrm{~g}$ \\
Nutrisource lipid (Sandoz Nutrition Corp.) $^{*}$ & $43 \mathrm{ml}$ \\
Nutrisource minerals for protein formulas (Sandoz $^{*}$ & $2.4 \mathrm{~g}$ \\
Nutrition Corp.) $^{*}$ & \\
Calcium gluconate $(10 \%)$ for injection & $2 \mathrm{ml}$ \\
Vitamin mixture (AIN-76) $\dagger_{\text {Riboflavin }}$ & $0.175 \mathrm{~g}$ \\
Choline chloride & $0.6 \mathrm{mg}$ \\
Water & $0.05 \mathrm{~g}$ \\
& q.s. \\
\end{tabular}

* Twelve $\mathrm{g}$ of powder provides $9.1 \mathrm{~g}$ protein as lactalbumin; $43 \mathrm{ml}$ of lipid provides $11.2 \mathrm{~g}$ of lipid, and $0.83 \mathrm{~g}$ lipid is provided from the Nutrisource protein packet. The mineral mix contains $0.6 \mathrm{~g}$ maltodextrins in each $2.4 \mathrm{~g}$.

$\dagger$ See References 5-7. Lactose $0.2 \mathrm{~g}$ was used as the carrier for the vitamins.
Table 2. Composition of tube feeding formula and rat milk (per $100 \mathrm{ml}$

\begin{tabular}{|c|c|c|}
\hline & Formula & Rat milk* \\
\hline Kcal, calculated & 159 & 159 \\
\hline Protein (g) & 9.1 & 9.2 \\
\hline Carbohydrate (g) & $2.8 \dagger$ & 3 \\
\hline Lipid (g) & 12.03 & 12.3 \\
\hline \multicolumn{3}{|l|}{ Minerals and electrolytes } \\
\hline Calcium (mg) & 320 & 330 \\
\hline Phosphorus (mg) & 116 & 229 \\
\hline Iron $(\mathrm{mg})$ & 1.8 & 0.61 \\
\hline Zinc (mg) & 1.5 & 1 \\
\hline Copper (mg) & 0.2 & 0.43 \\
\hline Magnesium (mg) & 35 & 0.01 \\
\hline Sodium (mg) & 160 & 66 \\
\hline Potassium (mg) & 268 & 140 \\
\hline Chlorine (mg) & 206 & 176 \\
\hline lodine (mg) & 0.15 & 0.1 \\
\hline Manganese (mg) & 4 & \\
\hline Selenium (mg) & 0.125 & \\
\hline Chromium (mg) & 0.125 & \\
\hline Molybdenum (mg) & 0.325 & \\
\hline \multicolumn{3}{|l|}{ Vitamins } \\
\hline Vitamin A (IU) & 70 & 70 \\
\hline Vitamin D (IU) & 17.5 & \\
\hline Vitamin E (mg) & 0.59 & 0.27 \\
\hline Vitamin K (mg) & 0.014 & \\
\hline Thiamin (mg) & 0.11 & 0.11 \\
\hline Riboflavin (mg) & 0.71 & 0.89 \\
\hline Pyridoxine (mg) & 0.12 & 0.076 \\
\hline Niacin (mg) & 0.52 & 2.2 \\
\hline Pantothenate (mg) & 0.28 & 0.84 \\
\hline Folic acid (mcg) & 35.0 & 2.5 \\
\hline Biotin (mcg) & 3.5 & 7.5 \\
\hline Vitamin B (mcg) & 0.175 & 2.5 \\
\hline Choline (mg) & 50 & 82 \\
\hline
\end{tabular}

* Composition of rat milk was derived from Reference 1.

$\dagger$ Lactose $2.2 \mathrm{~g}$; maltodextrins $0.6 \mathrm{~g}$.

stimulation of ${ }^{3} \mathrm{H}$-thymidine uptake by cultured human foreskin fibroblasts (18), as previously reported (19).

Rats were weighed daily and at the time of sacrifice organ weights were determined after careful dissection to remove connective tissue and fat before weighing with a precision balance $( \pm 0.01 \mathrm{~g})$. Differences were determined by paired $t$ test for changes in body weight of rats and Student's $t$ test for organ weights.

\section{RESULTS}

Intragastric feedings. Of the 42 pups maintained for the entire period on tube feeding, four pups (10\%) died within $24 \mathrm{~h}$ and were replaced immediately by litter mates. Throughout the remainder of the tube feeding studies, six rats died. Necropsy indicated that the rats dying within $24 \mathrm{~h}$ died with formula in their lungs. Of the six rats which died after $24 \mathrm{~h}$ of tube feeding, four showed necropsy findings consistent with aspiration that appeared to be due to dislodgement of the tubes and subsequent infusion of the formula into the hypopharynx. Two died, after 4 and 5 days of tube feeding, as a result of intestinal complications associated with intestinal distension, termed by Smart et al. (7) as "bloat." There was no evidence of intramural air or other finding suggestive of necrotizing enteritis.

In the tube feeding studies, 15 rats were used. Two of the group receiving EGF in the milk died, and one of those not receiving $E G F$ died. Analyses were made on data from seven rats receiving EGF and eight not receiving EGF. 
Body and organ weights. Changes in body weight in the 42 pups receiving orogastric tube feeding was compared with weights of 48 mother-fed pups is depicted in Figure 1. All rats gained similarly during the first 7 days. However, the intragastrically fed group gained weight slower during the subsequent days until sacrifice.

In the EGF study, the mother-fed pups receiving EGF showed a progressive decline in the rate of weight gain compared to the mother-fed control pups after the 2 nd day of EGF injections. The difference in rate of weight gain from days 2 to 7 in EGF treated mother-fed rats compared to those not receiving EGF was $+0.02,-0.2,-1.7,-2.2,-2.9$, and $-4.0 \mathrm{~g}$ during successive days of EGF injections. By contrast, the mean rate of weight gain in tube-fed rats without EGF in the formula was similar to mother-fed controls from day 2 until day 5 of tube feeding, but a decline in weight gain developed subsequently. The difference in weight gain of the tube-fed pups compared to mother-fed pups was $-0.1,-0.2,-0.2,-0.9,-1.7$, and $-3.0 \mathrm{~g}$ between days 2 and 7 . These changes were in the tube-fed pups receiving formula with EGF and were similar to the other tube-fed pups.

Table 3 lists the changes seen in the various groups during the EGF study. The first two columns compare the two mother-fed groups. Daily injections of pharmacologic doses of EGF resulted in significant changes in body weight, as well as of all the organs tested. EGF caused a significant $(p<0.04)$ reduction in the weight of liver, kidney, thyroid, and thymus. Conversely, EGF caused a significant increase in bowel length and weight of the

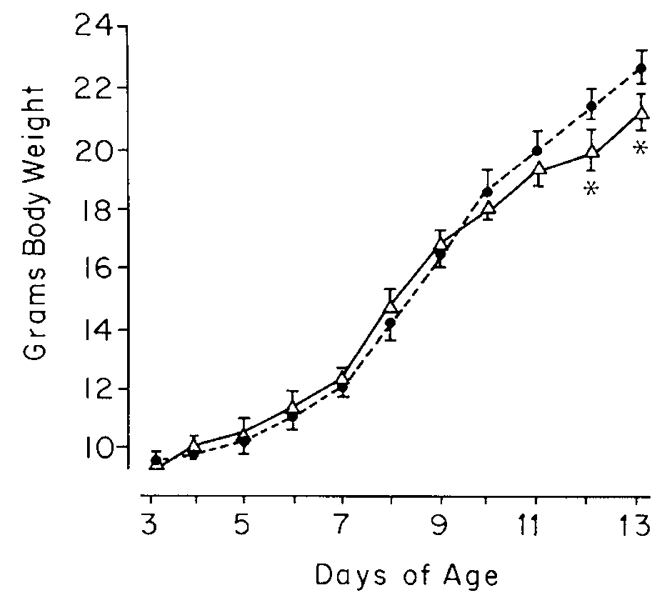

Fig. 1. Weights of tube-fed (solid line) and control (broken line) animals $(* p<0.05)$. Weights of tube-fed animals are adjusted for the weights of the tubes. stomach, pancreas, lung, and adrenal $(p<0.05)$. Both groups of tube-fed animals were similar whether they received EGF or not, and showed changes similar to those in the mother-fed EGF group. For example, body weight, weight of liver, kidney, and pancreas, and intestinal length were similar in both groups of tube fed pups as well as EGF treated mother-fed pups. Thyroid and thymus weights were similar to those in mother-fed animals not given EGF, but less than in the EGF-injected pups $(p<$ 0.03 ).

Table 4 summarizes the day of the eye opening and tooth eruption in the pups. Both groups of artificially fed pups showed early tooth eruption and eye opening, similar to that seen in the mother-fed EGF-treated pups.

\section{DISCUSSION}

We have found that intragastric feeding is a satisfactory and less invasive method for artificially rearing rat pups less than 10 days of age than the use of gastrostomies. The orogastric tubes can be easily inserted within the first few days of life without significant morbidity or mortality. We have also devised a modular formula that matches the published nutritional content of rat milk and can be modified to study the effect of varying the concentration of a single nutrient. The formula and method of delivery are also unique in that unlike other studies showing poor weight gain during the first few days of life the pups in this study showed weight gains similar to those of mother-fed pups $(1-7)$. Mortality in gastrostomized rat pups has been reported as $9 \%$ (one of 11 pups) (5), $25 \%$ (two of eight pups) (3), $29 \%$ (four of 14 pups given 24 feedings per day) (4), and $18 \%$ ( 10 of 56 pups given four feedings per day) (4). The mortality after $24 \mathrm{~h}$ of orogastric feedings was only $15 \%$ during 9 days of treatment. A significant number of deaths resulted in endotracheal tube placement, allowing immediate substitution of unaffected pups for completion of the study. We did note that by days 8 to 10 the pups became much more active, resulting in more frequent tube dislodgement. For this reason, the orogastric tube may be

Table 4. Time of tooth eruption and eyelid opening

\begin{tabular}{|c|c|c|c|c|c|c|c|c|c|}
\hline \multirow[b]{2}{*}{ Age } & \multirow[b]{2}{*}{ Study day } & \multicolumn{2}{|c|}{ MF } & \multicolumn{2}{|c|}{$\begin{array}{c}\mathrm{MF}+ \\
\mathrm{EGF}\end{array}$} & \multicolumn{2}{|c|}{$\mathrm{TF}$} & \multicolumn{2}{|c|}{$\begin{array}{l}\mathrm{TF}+ \\
\mathrm{EGF}\end{array}$} \\
\hline & & TE* & $\mathrm{EO}$ & $\mathrm{TE}$ & $\mathrm{EO}$ & $\mathrm{TE}$ & $\mathrm{EO}$ & $\mathrm{TE}$ & $\mathrm{EO}$ \\
\hline 9 & 6 & $0 / 8$ & $0 / 8$ & $3 / 8$ & $4 / 8$ & $3 / 7$ & $4 / 7$ & $4 / 6$ & $4 / 6$ \\
\hline 10 & 7 & $2 / 8$ & $0 / 8$ & $5 / 8$ & $7 / 8$ & $5 / 7$ & $6 / 7$ & $6 / 6$ & $6 / 6$ \\
\hline 12 & 9 & $6 / 8$ & $7 / 8$ & $8 / 8$ & $8 / 8$ & $7 / 7$ & $7 / 7$ & $6 / 6$ & $6 / 6$ \\
\hline
\end{tabular}

* TE, tooth eruption; EO, eye open, numeration refers to number of pups with positive finding and denominator of the total number of pups.

Table 3. Body wt and organ sizes in rat pups*

\begin{tabular}{lcccc}
\hline & MF $\dagger$ & MF-EGF $\dagger$ & TF & TF-EGF \\
\hline Body wt (g) & $24 \pm 0.7$ & $20 \pm 0.9$ & $21 \pm 0.2 \ddagger$ & $20 \pm 0.8 \ddagger$ \\
Liver (mg) & $1217 \pm 79$ & $881 \pm 81$ & $694 \pm 76 \ddagger$ & $710 \pm 63 \ddagger$ \\
Kidney (mg) & $332 \pm 12$ & $242 \pm 27$ & $227 \pm 5.2 \ddagger$ & $238 \pm 11.8 \ddagger$ \\
Thyroid (mg) & $105 \pm 13$ & $71 \pm 10$ & $56.6 \pm 6.2 \S$ & $62 \pm 9.1 \S$ \\
Thymus (mg) & $110 \pm 6.2$ & $67 \pm 6.4$ & $41.2 \pm 6.3 \S$ & $38.5 \pm 7.4 \S$ \\
Stomach (mg) & $170 \pm 0.16$ & $198 \pm 4.6$ & $158 \pm 9.6 \|$ & $154 \pm 8 \ddagger$ \\
Intestine (cm) & $42 \pm 0.9$ & $47.5 \pm 1.6$ & $47.3 \pm 1.7 \ddagger$ & $48.4 \pm 2$ \\
Pancreas (mg) & $85 \pm 7$ & $104 \pm 10$ & $99.5 \pm 6 \|$ & $106 \pm 11$ \\
Lung (mg) & $426 \pm 12$ & $667 \pm 32$ & $427 \pm 19 \|$ & $486 \pm 21$ \\
Adrenal (mg) & $4.7 \pm 0.1$ & $6.4 \pm 0.2$ & $4.1 \pm 0.44 \|$ & $4.3 \pm 0.3 \dagger$ \\
\hline
\end{tabular}

* MF, mother-fed; MF-EGF, mother-fed plus EGF (0.1, $\mu \mathrm{g} / \mathrm{g}$ body weight); TF, tube-fed an artificial formula; TF-EGF, TF plus EGF (62 ng/ml) in formula.

$\uparrow$ Comparisons between MF and MF-EGF were all different $(0.01>p<0.05)$.

$\because$ Different from"MF only $(p<0.03)$.

$\S$ Different from both the MF and MF-EGF groups $(p<0.04)$

$\|$ Different from MF-EGF only $(p<0.02)$. 
most efficacious in younger pups and gastrostomy in the older pups.

The formula described herein is an improvement over those used by earlier investigators, because it more closely resembles rat milk, allows for manipulation of vitamin or major nutrient content, and is less hypertonic than those based on cow's milk (452 versus $670 \mathrm{mosmol} / \mathrm{kg}$, respectively $(3,7)$.

Another advantage of the formula is its smooth consistency. Our attempts to use a commercial formula for rat pups (i.e. no. 719001, Dyets, Inc., Bethlehem, PA) were unsuccessful, because the formula was so granular that it occluded the small feeding tubes. The protein, lipid, and mineral constituents of the formula we describe were derived from a modular tube feeding formula designed for humans. The micropulverized Nutrisource mineral mixture seems to be crucial to the smooth consistency of the formula. No tube became obstructed during infusion of the formula described herein.

It has been reported that bubbling air via a hose through the water bath agitates the cups enough to make anogenital stroking unneccesary (2), but our experience with 42 pups indicated that bubbling was inadequate since survival was much improved (from $40 \%$ to the current $85 \%$ ) when direct anogenital stimulation was provided.

Previous investigations have demonstrated the trophic effects of EGF on several tissues in the developing mouse $(1,20)$, rat, and rabbit (21). There is evidence to suggest that EGF acts primarily on stem cells to promote proliferation and terminal differentiation (22), although the exact mechanism whereby the effects of EGF occurs in developing cells is not known.

Breast milk induces hyperplasia of the enteric mucosa in newborn puppies (23). Morphologic (22, 24), enzymic $(20,24)$, and functional (19) studies in newborn animals also suggest a possible role of EGF in promoting growth, differentiation, and functional maturation of the digestive tract. Thus, EGF, which is present in milk $(10,11)$, may be an important factor promoting normal intestinal maturation. However, studies on the effects of EGF have been performed in animals that receive both EGFcontaining milk from their mothers and additional EGF administered in doses greater than $0.1 \mu \mathrm{g} / \mathrm{g}$ body weight/day, either subcutaneously or intraperitoneally. These doses of EGF were several times greater than the total amount of EGF that the human infant receives in its mother's milk each day. Thus, the true physiologic role of milk EGF has not yet been defined.

We postulated that EGF normally present in milk is necessary to initiate normal growth and development of the intestine during the first $2 \mathrm{wk}$ of life. In order to test this hypothesis, the animal model for feeding EGF-deficient milk was developed. However, our findings suggest that artificial feeding alone is associated with changes in intestinal length similar to those seen with pharmacologic injections of EGF. In addition, the changes in body weight and several other organ weights were also similar to those in the EGF-treated mother-fed pups. The observed similarities between the mother-fed animals receiving EGF and the tube-fed animals imply that either the formula or the method of feeding can induce "EGF-like" changes and suggest that some of the changes attributed to EGF may be nonspecific responses possibly through recruitment of other hormones (25). For example, the marked reduction in thymic weight in the artificially fed animals is suggestive of prolonged stress, with resultant hypersecretion of corticosterone and possibly other hormones (e.g. growth hormone, thyroxin, prolactin, catecholamines). This concept is supported by premature eye opening in all the tubefed animals, a response that can be induced by either EGF, thyroxin, or glucocorticoids (8).

Hoath (26) has recently shown that the maximum effect of EGF on the reduction in body weight and hepatic weight occurs before 3 days of age. Although our studies were intiated after this period, it is apparent that systemic injections of EGF after 3 days of age can cause a substantial reduction in body weight as well as alteration in weights of several organs and an increase in intestinal length.

It appears, however, that the physiologic role of EGF contained in milk cannot be clearly delineated using the artificially fed rat model. Studies on the effects of artificial feeding on other hormones known to be involved in organ maturation will be necessary to determine the mechanism of the apparent stress effect. Agents that specifically impair EGF production or block its receptor binding may best answer the question of the physiologic role of EGF during normal maturation.

\section{REFERENCES}

1. Dymsza HA, Czajka DM, Miller SA 1964 Influence of artificial diet on weight gain and body composition of the neonatal rat. J Nutr 84:100-106

2. Hall WG 1975 Weaning and growth of artificially reared rats. Science 190:1313-1315

3. Messer M, Thoman EB, Terrasa AG, Dallman RP 1969 Artificial feeding of infant rats by continuous gastric infusion. J Nutr 98:404-410

4. Anderson TA, Raffety CJ, Birkhofer KK, Fomon SJ 1980 Effect of feeding frequency on growth and body composition of gastrostomized rat pups. J Nutr 110:2375-2380

5. Diaz J, Moore E, Petracca F, Schacher J, Stamper C 1981 Artificial rearing of preweanling rats: the effectiveness of direct intragastric feeding. Physiol Behav 27:1103-1105

6. Miller SA, Dymsza HA 1963 Artificial feeding of neonatal rats. Science 141:517-518

7. Smart JL, Stephens DN, Katz HB 1983 Growth and development of rats artificially reared on a high or low plane of nutrition. Br J Nutr 49:497-507

8. Cohen S 1962 Isolation of a mouse submaxillary gland protein accelerating incisor eruption and eyelid opening in the newborn animal. $J$ Biol Chem 237:1555-1562

9. Carpenter G, Cohen S 1979 Epidermal growth factor. Ann Rev Biochem 48:193-216

10. Moran JR, Courtney ME, Orth DN, Vaughn R, Greene HL 1983 Epidermal growth factor in human milk: daily production and diurnal variation during early lactation in mothers delivering at term and premature gestation. $\mathfrak{J}$ Pediatr 103:402-405

11. Read LC. Francis GL, Wallace JC, Ballard FJ 1985 Growth factor concentrations and growth-promoting activity and human milk following premature birth. J Dev Physiol 7:135-145

12. Cohen S, Carpenter G 1975 Human epidermal growth factor: Isolation and chemical and biological properties. Proc Natl Acad Sci USA 72:1317-1321

13. Savage CR Jr, Inagami T, Cohen S 1972 The primary structure of epidermal growth factor. J Biol Chem 247:7612-7619

14. Forgue-Lafitte ME, Laburthe M, Chamblier MC, Moody AJ, Rosselin G 1980 Demonstration of specific receptors for EGF-urogastrone in isolated rat intestinal epithelial cells. FBS Lett 114:243-246

15. Thornbury W, Matrisian L, Magum B, Koldovsky O 1984 Gastrointestinal absorption of epidermal growth factor in suckling rats. Am $\mathrm{J}$ Physiol 246(Gastrointest Liver Physiol 9):G-80-G85

16. Savage CR Jr, Cohen S 1972 Epidermal growth factor and a new derivative: Rapid isolation procedures and biological and chemical characterization. $\mathrm{J}$ Biol Chem 247:7609-7611

17. Hirata Y, Orth DN 1979 Epidermal growth factor (urogastrone) in human fluids: size heterogeneity. J Clin Endocrinol Metab 48:673-679

18. Hirata $Y$, Orth DN 1979 Conversion of high molecular weight human epidermal growth factor (hEGF)/urogastrone (UG) to small molecular weight hEGF/UG by mouse EGP-associated arginine esterase. J Clin Endocrinol Metab 49:481-483

19. Oka Y, Ghishan FK, Greene HL, Orth DN 1983 Effect of mouse epidermal growth factor/urogastrone on the functional maturation of rat intestine. Endocrinology 112:940-944

20. Malo C, Menard D 1982 Influence of epidermal growth factor on the development of suckling mouse intestinal mucosa. Gastroenterology 83:28-35

21. Catterton WZ, Escobedo MB, Sexson WR, Gray ME, Sundell HW, Stahlman MT 1979 Effect of epidermal growth factor on lung maturation in fetal rabbits. Pediatr Res 13:104-108

22. Beaulieu JF, Calvert R 1981 The effect of epidermal growth factor (EGF) on the differentiation of the rough endoplasmic reticulum in fetal mouse small intestine in organ culture. J Histochem Cytochen 29:765-770

23. Schwartz S. Heird WC 1981 Further studies of colostrum-stimulated enteric mucosal growth. Pediatr Res 154:637(abstr)

24. Feldman EJ, Aures D, Grossman MI 1978 Epidermal growth factor stimulates ornithine decarboxylase activity in the digestive tract of mouse. Proc Soc Exp Biol Med 159:400-402

25. Polk DH, Humme JA, Padbury JF, Lom RW, Fisher DA 1986 Epidermal growth factor administration increases plasma adrenocorticotropin levels in fetal lambs. Pediatr Res 20:195A

26. Hoath SB 1986 Treatment of the neonatal rat with epidermal growth factor: Differences in time and organ response. Pediatr Res 20:468-472 